American Journal of Environmental Sciences 8 (2): 95-103, 2012

ISSN 1553-345X

(C) 2012 Science Publications

\title{
Estimation of Pan Coefficient using M5 Model Tree
}

\author{
${ }^{1}$ Pakorn Ditthakit and ${ }^{2}$ Chaiyuth Chinnarasri \\ ${ }^{1}$ School of Engineering and Resources, \\ Walailak University, Nakhon Si Thammarat 80160, Thailand \\ ${ }^{2}$ Water Resources Engineering and Management Research Center (WAREE), \\ Department of Civil Engineering, Faculty of Engineering, \\ King Mongkut's University of Technology Thonburi, Bangkok 10140, Thailand
}

\begin{abstract}
Problem statement: Pan Evaporation has extensively been used for estimating reference Evapotranspiration (ETo) due to its simplicity, low cost, ease of data interpretation and application and suitability for locations with limited availability of meteorological data. With this method, the pan coefficient (Kp) is a key element to be determined as well as the pan Evaporation (Ep) data. Approach: This study presents the development of new pan coefficient (Kp) equations for Class A pan and Colorado sunken pan under green and dry fetch conditions by using M5 model tree based on soft computing technique. The Kp values were taken from FAO-24 Kp table for the development of Kp equations. Results: The results of the study indicate the usefulness and applicability of the M5 model tree in developing Kp equations. Those proposed equations based on the M5 model tree gave better performance in estimating $\mathrm{Kp}$ values than the previous $\mathrm{Kp}$ equations as well as the new $\mathrm{Kp}$ equations developed by indicator regression technique. Conclusion: M5 model tree gave more accuracy in estimating Kp values. The new proposed Kp equations can be reliably used.
\end{abstract}

Key words: Estimating equation, indicator regression technique, M5 model tree, soft computing

\section{INTRODUCTION}

Accurate and reliable reference Evapotranspiration (ETo) estimation is an essential hydrological parameter for optimum water resources planning and farm irrigation scheduling. In recent years, several methods for estimating ETo from meteorological data have been proposed. For example, Turc (1961) proposed equation for estimating ETo using three meteorological data, including incoming solar radiation, mean daily air temperature at $2 \mathrm{~m}$ height and mean daily relative humidity. Priestley and Taylor (1972) developed equation for ETo estimation depending on daily mean air temperature, net radiation, heat flux density to the ground and atmospheric pressure. Hargreaves and Samani (1985) proposed ETo estimating equation using three meteorological data, including extraterrestrial radiation, maximum daily air temperature and minimum daily air temperature at $2 \mathrm{~m}$ height.

The FAO Penman-Monteith method is now recommended as a reference standard method for computing ETo. This meteorological-based method is complex and requires a significant number of meteorological data, i.e., air temperature, humidity, radiation and wind speed data. Often, the meteorological data are missing or incomplete due to instrument failure, contamination by measurement errors. For this reason, the pan Evaporation (Ep) has become widespread method due to its simplicity, low cost, ease of data interpretation and application and suitability for locations with limited availability of meteorological data (Phene and Campbell, 1975; Stanhill, 2002; Trajkovic, 2009). Indeed, the ETo can be determined as the product of a pan coefficient (Kp) and Ep.

Two types of evaporation pan, i.e., class $\mathrm{A}$ and Colorado sunken pans are commonly used. Colorado sunken pans are sometimes preferred in crop water requirement studies due to giving better ETo estimation; however, its maintenance is more difficult and leaks are not visible. Two cases of evaporation pan sitting are: (1) the pan is sited on a short green (grass) cover and surrounded by fallow soil and (2) the pan is sited on fallow soil and surrounded by a green crop.

Several Kp equations have been suggested based on the original and the FAO-24 Kp tables using linear, nonlinear and indicator regression techniques or combinations thereof. Frevert et al. (1983); Cuenca (1989); Snyder (1992) and Raghuwanshi and Wallender (1998) developed regression equations for predicting the Kp values for the FAO Class A pan placed in short

Corresponding Author: Chaiyuth Chinnarasri, Water Resources Engineering and Management Research Center (WAREE), Department of Civil Engineering, Faculty of Engineering, King Mongkut's University of Technology Thonburi, Bangkok 10140, Thailand 
green cropped area based on FAO-24 Kp table. Cuenca (1989) modified Kp equation as proposed by Frevert et al. (1983) by rounding off the coefficients of equation. Snyder (1992) used the representative values to represent the category data of wind run and relative humidity and applied least-squares regression approach for predicting $\mathrm{Kp}$ values.

To develop $\mathrm{Kp}$ equation, Raghuwanshi and Wallender (1998) applied indicator regression technique, which is widely accepted approach for developing a relationship between categorical and quantitative data. Three Kp equations were developed based on the original data table (Allen and Pruitt, 1991; Orang, 1998; Grismer et al., 2002). Allen and Pruitt (1991) used stepwise and multivariate general linear regression procedures for FAO Class A pan placed in short green cropped area. Orang (1998) used linear regression technique and interpolation between fetch distances. Grismer et al. (2002) proposed an equation namely a modified Snyder (1992) equation. Allen (1998) and Abdel-Wahed and Snyder (2008) proposed Kp equation for the FAO Class A pan placed in dry fallow area.

Allen (1998) proposed two Kp equations for Colorado sunken pans surrounded by green and dry fetch conditions. Many attempts have been made for evaluation of pan coefficient in different regions and climates (Grismer et al., 2002; Irmak et al., 2002; Snyder et al., 2005; Ghare and Porey, 2008; Gundekar et al., 2008; Khoob, 2009).

M5 model tree, one of soft computing techniques, is gaining popularity in data analysis in sevearl branches of the science as well as water resources engineering problems. It mimics human mind dealing with imprecision, uncertainty, partial truth and approximation to achieve tractability, robustness and low solution cost (Mitra and Acharya, 2003). It is, hence, appropriate for solving hard tasks which an exact solution cannot be determined.

The examples of applying M5 model tree for water-related problems, i.e., rainfall-runoff modeling (Solomatine and Dulal, 2003), flood forecasting (Solomatine and Xue, 2004), water level-discharge relationship (Bhattacharya and Solomatine, 2005) and sedimentation modeling (Bhattacharya and Solomatine, 2006). The soft computing techniques are relatively new for predicting pan coefficient values. From literature reviews, few researches were found. For example, Trajkovic et al. (2000) applied radial basis function network to estimate FAO Blanney-Criddle $b$ factor. Trajkovic et al. (2001) estimated the FAO Penman c factor using radial basis function network. Ditthakit and Chinnarasri (2011) presented the application of neuro-genetic approach for estimating pan evaporation coefficient for class a pan and Colorado sunken pan under green and dry fetch conditions. Although using neuro-genetic approach could be obtained higher performance in estimaitng $\mathrm{Kp}$ values when compared to previous methods, the explicit equations were not revealed.

It is, therefore, interested to investigate the performance of M5 model tree for pan coefficient estimation. The explicit equation would be determined in form of if-the rule.The purpose of this study is to apply M5 model tree for developing new pan coefficient equations for class $\mathrm{A}$ and Colorado sunken pans under green and dry fetch conditions. The indicator regression were also applied herein to determine pan coefficient equations for Class A pan placed in dry fallow area and Colorado sunken pan placed in short green cropped area and dry fallow area. The performance comparisons between the new proposed equations and previous equations is also presented and discussed.

\section{MATERIALS AND METHODS}

M5 model tree: M5 model tree was first introduced by Quinlan (1992). The mode is based on a divide-andconquer approach for developing a relationship between independent and dependent variables. Unlike decision tree which is used for categorical data, It can be used for both qualitative (categorical) and quantitative data (Quinlan, 1986; 1992; Mitchell, 1997). This model is analogous to piece-wise linear functions with the combination of linear regression and regression tree concepts (Witten and Frank, 2005). The linear regression approach represents the relation of data set with a linear regression equation. For the regression tree approach, the data set is split up into subsets (also called leaves, child nodes, or sub-trees) and their relations at subsets (or leaves) are represented with averaged numeric values.

The regression tree is much larger and more complex than the regression equation. Like regression tree approach, the model tree make a splitting the data set into subsets (or leaves), but the relations of data set at its leaves are represented with linear regression equations, instead of averaged numeric values. The model tree can hence represent more sophisticated relations than either linear regression or regression trees and it is smaller in structure and more comprehensible than the regression tree.

In applying M5 model tree for nominal (or categorical) attribute like $\mathrm{Kp}$ equations development, all nominal attributes are transformed into binary variables that are then treated as numeric before constructing a model tree. For each nominal attribute, 
the average class value corresponding to each possible value in the enumeration is calculated from the training instances and the values in the enumeration are sorted according to these averages. Then, if the nominal attribute has $\mathrm{k}$ possible values, it is replaced by $\mathrm{k}-1$ synthetic binary attributes, the $\mathrm{i}$ th being 0 if the value is one of the first $i$ in the ordering and 1 otherwise. Thus all splits are binary: they involve either a numeric attribute or a synthetic binary one, treated as a numeric attribute.

Building M5 model tree consists of three different stages (Quinlan, 1992; Solomatine and Xue, 2004; Pal, 2006). The first stage involves splitting of the data into subsets to create a decision tree. The splitting criterion is based on treating the standard deviation of the class values that reach a node as a measure of the error at that node and calculating the expected reduction in this error as a result of testing each attribute at that node. The formula for computing the Standard Deviation Reduction (SDR) is Eq. 1:

$$
\operatorname{SDR}=\operatorname{sd}(T)-\sum_{i} \frac{\left|T_{i}\right|}{|T|} \times \operatorname{sd}\left(T_{i}\right)
$$

where, $\mathrm{T}$ represents a set of examples that reaches the node; $\mathrm{T}_{\mathrm{i}}$ represents the subset of examples that have the $i$ th outcome of the potential set and $\mathrm{sd}$ represents the standard deviation.

As a result of the splitting process, the standard deviation values of the data set in child nodes (sub-trees, or lower nodes) are less than those of parent nodes (higher nodes). After examining all the possible splits, the one that maximizes the expected error reduction was chosen. However, this division often produces a large tree-like structure that lead to overfit structure or poor generalizer. To avoid this problem, in second stage the overgrown tree is pruned and then the pruned sub-trees are replaced with linear regression functions. The pruning process concerns with merging some of the lower sub-trees into one node. Finally, the smoothing process is performed to compensate for the sharp discontinuities that will inevitably occur between adjacent linear models at the leaves of the pruned trees, particularly for some models constructed from a smaller number of training examples.

In smoothing, the adjacent linear equations are updated in such a way that the predicted outputs for the neighboring input vectors corresponding to the different equations are becoming close in value. This process substantially increases the accuracy of prediction (Quinlan, 1992; Witten and Frank, 2005). Example of M5 model tree algorithm is shown in Fig. 1. In Fig. 1a, it is the splitting of the input space $\mathrm{X}_{1} \times \mathrm{X}_{2}$ (independent variables) by M5 model tree algorithm with 6 linear regression models at its leaves, labeled LM1 through LM6. Each model is a linear regression model in general form of $\mathrm{y}=\mathrm{a} 0+\mathrm{a} 1 \times 1+\mathrm{a} 2 \times 2$, which $\mathrm{a} 0$, a1 and $\mathrm{a} 2$ are linear regression coefficients. In Fig. $1 b$, it is the details of its relations in form of tree diagram, in which $\mathrm{LM}_{1}$ to LM6 are in leave level.

Existing pan coefficient (kp) equations: To evaluate the performance of the new proposed pan coefficient (Kp) equations for Class $\mathrm{A}$ and Colorado sunken pans, the different existing Kp equations as listed in Table 1 are used as benchmark. All equations in Table 1 were developed based on FAO-24 Kp table. The Kp values are the function of daily mean relative humidity, $\mathrm{RH}$ (\%), daily mean wind speed at $2 \mathrm{~m}$ height, $\mathrm{U}_{2}\left(\mathrm{~km}^{-1}\right)$ and fetch distance, $\mathrm{F}(\mathrm{m})$. The representative techniques for some equations can be concluded as follows.

Cuenca (1989) used representative (mean) values of each range of wind run $(50,300,550$ and850 $\mathrm{km}^{-1}$, representing the wind run categories of $<175$, $175-425,425-700$ and $>700 \mathrm{~km}^{-1}$, respectively) and relative humidity $(30,55$ and $80 \%$, representing the relative humidity categories of $40,40-70 \geq 70 \%$, respectively). Snyder (1992) used representative (mean) values of each range of wind run $(175,300$, 562 and $700 \mathrm{~km}^{-1}$, representing the wind run categories of $<175, \quad 175-425,425-700$ and $>700 \mathrm{~km}^{-1}$, respectively) and relative humidity (40, 55 and $70 \%$, representing the relative humidity categories of $\leq 40$, $40-70, \geq 70 \%$, respectively).

In Eq. 4, which was proposed by Raghuwanshi and Wallender (1998), $X_{1}$ represents $\ln (F) ; X_{2}, X_{3}$ and $X_{4}$ represent wind run categories of 175-425, 425-700 and $700 \mathrm{~km}^{-1}$, respectively; and $\mathrm{X}_{5}$ and $\mathrm{X}_{6}$ represent relative humidity categories of 40-70 and 70\%, respectively. The values of variables $\mathrm{X}_{2}, \mathrm{X}_{3}, \mathrm{X}_{4}, \mathrm{X}_{5}$ and $\mathrm{X}_{6}$ are equal to 0 when the category do not present, or equal to 1 when the category present. The unit of daily mean wind speed at 2 $\mathrm{m}$ height, $\mathrm{U}_{2}$ in the Eq. 5-9 is $\mathrm{m} \mathrm{sec}^{-1}$. According to Abdel-Wahed and Snyder (2008), the mean wind speeds 2, 3.5, 6.5 and8 $\mathrm{m} \mathrm{sec}^{-1}$ were chosen to represent the wind run categories $<2,2-58$ and, $5->8 \mathrm{~m} \mathrm{sec}^{-1}$ and the mean of relative humidity 30,55 and $75 \%$ were selected to represent the relative humidity categories of $\leq 40,40$ $70 \geq 70 \%$.

Development of Kp equations using m5 model tree: To develop Kp equations based on M5 model tree for Class A pan placed in short green cropped area (Case I), Class A pan placed in dry fallow area (Case II), Colorado sunken pan placed in short green cropped area (Case III) and Colorado sunken pan placed in dry fallow area (Case IV), data sets based on Kp FAO-24 table (Allen, 1998) were used. 


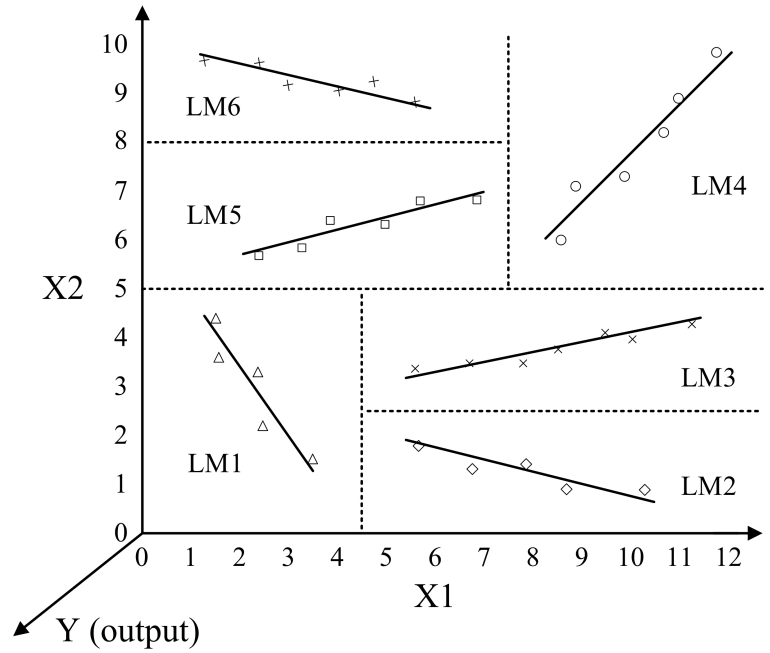

(a)

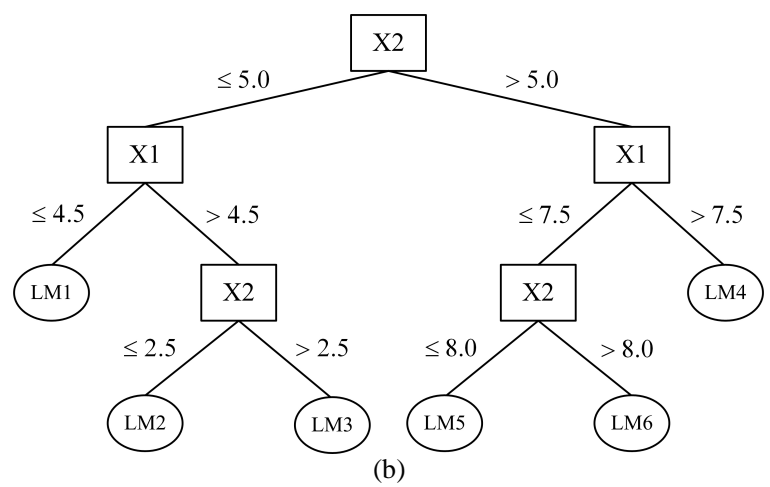

(b)

Fig. 1: Example of M5 model tree algorithm with 6 linear regression models

Table 1: The existing Kp equations

\begin{tabular}{ll}
\hline Author (year) & $\mathrm{Kp}$ equations \\
\hline $\begin{array}{l}\text { Class A pan placed in short } \\
\text { green cropped area (Case I) }\end{array}$ & \\
Cuenca (1989) & $\mathrm{Kp}=0.475-2.4 \times 10^{-4} \mathrm{U}_{2}+5.16 \times 10^{-3} \mathrm{RH}$ \\
& $+1.18 \times 10^{-3} \mathrm{~F}-1.6 \times 10^{-5} \mathrm{RH}^{2}-1.01 \times 10^{-6} \mathrm{~F}^{2}$ \\
& $-8.0 \times 10^{-9} \mathrm{RH}^{2} \mathrm{U}_{2}-1.0 \times 10^{-8} \mathrm{RH}^{2} \mathrm{~F}$ \\
Snyder (1992) & $\mathrm{Kp}=0.482-0.000376 \mathrm{U}_{2}+0.024 \ln (\mathrm{F})+0.0045 \mathrm{RH}$ \\
Raghuwanshi and & $\mathrm{Kp}=0.5944+0.0242 \mathrm{X}_{1}-0.0583 \mathrm{X}_{2}-0.1333$ \\
Wallender (1998) & $\mathrm{X}_{3}-0.2083 \mathrm{X}_{4}+0.0812 \mathrm{X}_{5}+0.1344 \mathrm{X}_{6}$ \\
Allen (1998) & $\mathrm{Kp}=0.108-0.0286 \mathrm{U}_{2}+0.0422 \ln (\mathrm{F})+0.1434$ \\
& $\ln (\mathrm{RH})-0.000631[\ln (\mathrm{F})]^{2} \ln (\mathrm{RH})$ \\
Class A pan placed in & \\
dry fallow area (Case II) & \\
Allen (1998) & $\mathrm{Kp}=0.61+0.00341 \mathrm{RH}-0.000162 \mathrm{U}_{2} \mathrm{RH}$ \\
& $-0.00000959 \mathrm{U}_{2} \mathrm{~F}+0.00327 \mathrm{U}_{2} \ln (\mathrm{F})$ \\
& $-0.00289 \mathrm{U}_{2} \ln \left(86.4 \mathrm{U}_{2}\right)-0.0106 \ln \left(86.4 \mathrm{U}_{2}\right)$ \\
Abdel-Wahed and & $\ln (\mathrm{F})+0.00063[\ln (\mathrm{F})]^{2} \ln \left(86.4 \mathrm{U}_{2}\right)(6)$ \\
Snyder (2008) & $\mathrm{Kp}=0.62407-0.02660 \ln (\mathrm{F})+0.00028 \mathrm{U}$ \\
Colorado sunken pan & $+0.00326 \mathrm{RH}$ \\
placed in short green & \\
cropped area (Case III) & \\
Allen (1998) & $\mathrm{Kp}=0.87+0.119 \ln (\mathrm{F})-0.0157$ \\
& {$\left[\ln \left(86.4 \mathrm{U}_{2}\right]^{2}-0.0019[\ln F]-2 \ln \left(86.4 \mathrm{U}_{2}\right)\right.$} \\
& $+0.013 \ln \left(86.4 \mathrm{U}_{2}\right) \ln (\mathrm{RH})$ \\
Colorado sunken pan & $-0.000053 \ln \left(86.4 \mathrm{U}_{2}\right) \ln (\mathrm{F}) \mathrm{RH}$ \\
placed in dry fallow & \\
area (Case IV) & \\
Allen (1998) & $\mathrm{Kp}=1.145-0.080 \mathrm{U}_{2}+0.000903\left(\mathrm{U}_{2}\right)^{2}$ \\
& $\ln (\mathrm{RH})-0.0964 \ln (\mathrm{F})+0.0031 \mathrm{U}_{2} \mathrm{In}(\mathrm{F})$ \\
& $+0.0015[\ln (\mathrm{F})]^{2} \ln (\mathrm{RH})$ \\
\hline
\end{tabular}

From this table, the fetch distance is quantitative data and the daily mean relative humidity and daily mean wind speed are qualitative (or categorical) data. The $\mathrm{Kp}$ value is dependent variable and other data, i.e., wind speed, fetch distance and mean relative humidity are independent variables.

Table 2 presents the total number of samples of 48 for Cases II, II and IV and the total number of samples of 36 for the Case III. Columns 2, 8 and 9 are input variables or independent variables and Columns 10-13 are output variables or dependent variables for cases I to IV, respectively. The ten-fold cross validation was selected for model verification. The novel proposed Kp equations based on M5 model tree algorithm was built with the help of Weka learning tool (version 3.6.0), which is public domain software (Witten and Frank, 2005).

Development of $\mathrm{Kp}$ equations using indicator regression: To evaluate the performance of M5 model tree, the indicator regression technique was used herein to develop Kp equations for Class A pan placed in dry fallow area (Case II), Colorado sunken pan placed in short green cropped area (Case III) and Colorado sunken pan placed in dry fallow area (Case IV). This technique was used for developing Kp equation for Class A pan placed in short green cropped area (Case I) by Raghuwanshi and Wallender (1998). Indicator regression (Draper and Smith, 1981; Milton and Arnold, 1994; Raghuwanshi and Wallender, 1998) is technique which use for developing a relationship between independent and dependent variables based on multiple linear regression method. This technique has been widely used in the areas of transportation engineering and social sciences. The advantage of this technique over others is independent variables can be both qualitative (categorical) and quantitative data. Indicator regression technique uses n-1 indicator (dummy) variables to represent categorical variables consisting of $\mathrm{n}$ classes. In this study, categorical data of daily mean relative humidity $(\mathrm{RH})$ and daily mean wind speed $\left(\mathrm{U}_{2}\right)$ include 3 and 4 classes, respectively. Hence, the total of six dependent variables, that is, one for fetch distance $(F)$, two for daily mean relative humidity $(\mathrm{RH})$ and three for daily mean wind speed $\left(\mathrm{U}_{2}\right)$ are required.

The multiple regression equation can be expressed as Eq. 10:

$\mathrm{Kp}=\beta_{0}+\beta_{1} \mathrm{X}_{1}+\beta_{2} \mathrm{X}_{2}+\beta_{3} \mathrm{X}_{3}$ $+\beta_{4} X_{4}+\beta_{5} X_{5}+\beta_{6} X_{6}$ 
Am. J. Environ. Sci., 8 (2): 95-103, 2012

Where:

$\mathrm{Kp}=$ The pan coefficient;

$\beta \mathrm{i} \quad=$ Regression coefficients;

$\mathrm{X}_{1} \quad=$ Natural logarithm (ln) of fetch distance in $\mathrm{m}$;
$\mathrm{X}_{2}, \mathrm{X}_{3}, \mathrm{X}_{4}=$ Wind run categories of $175-425,425$ 700 and $700 \mathrm{~km}^{-1}$, respectively

$\mathrm{X}_{5}, \mathrm{X}_{6}=$ Relative humidity categories of 40-70 and $70 \%$, respectively

Table 2: Data preparation for Kp equations development

\begin{tabular}{|c|c|c|c|c|c|c|c|c|c|c|c|c|}
\hline \multirow[b]{2}{*}{$\begin{array}{l}\text { Num of } \\
\text { data } \\
\text { (1) }\end{array}$} & \multirow[b]{2}{*}{$\begin{array}{l}\text { In }(F) \\
\text { X1 } \\
(2)\end{array}$} & \multicolumn{5}{|c|}{ Indicator regression } & \multicolumn{2}{|c|}{ M5 model tree } & \multicolumn{2}{|l|}{$\mathrm{U}_{2}$} & \multicolumn{2}{|l|}{ RH } \\
\hline & & $\begin{array}{l}X 2 \\
(3)\end{array}$ & $\begin{array}{l}\mathrm{X} 3 \\
(4)\end{array}$ & $\begin{array}{c}\mathrm{X} 4 \\
(5)\end{array}$ & $\begin{array}{l}\mathrm{X} 5 \\
(6)\end{array}$ & $\begin{array}{l}\text { X6 } \\
\text { (7) }\end{array}$ & $\begin{array}{c}\mathrm{U}_{2} \\
(8)\end{array}$ & $\begin{array}{r}\text { RH } \\
(9)\end{array}$ & $\begin{array}{c}\mathrm{Kp}^{\mathrm{I}} \\
(10)\end{array}$ & $\begin{array}{c}\mathrm{Kp}^{\mathrm{II}} \\
(11)\end{array}$ & $\begin{array}{c}\mathrm{Kp}^{\mathrm{III}} \\
(12)\end{array}$ & $\begin{array}{c}\mathrm{Kp}^{\mathrm{IV}} \\
(13)\end{array}$ \\
\hline 1 & 0.0 & 0 & 0 & 0 & 0 & 0 & $<175$ & $<=40$ & 0.55 & 0.70 & 0.75 & 1.10 \\
\hline 2 & 0.0 & 0 & 0 & 0 & 1 & 0 & $<175$ & $40-70$ & 0.65 & 0.80 & 0.75 & 1.10 \\
\hline 3 & 0.0 & 0 & 0 & 0 & 0 & 1 & $<175$ & $>=70$ & 0.75 & 0.85 & 0.80 & 1.10 \\
\hline 4 & 0.0 & 1 & 0 & 0 & 0 & 0 & $175-425$ & $<=40$ & 0.50 & 0.65 & 0.65 & 0.95 \\
\hline 5 & 0.0 & 1 & 0 & 0 & 1 & 0 & $175-425$ & $40-70$ & 0.60 & 0.75 & 0.70 & 0.95 \\
\hline 6 & 0.0 & 1 & 0 & 0 & 0 & 1 & $175-425$ & $>=70$ & 0.65 & 0.80 & 0.70 & 0.95 \\
\hline 7 & 0.0 & 0 & 1 & 0 & 0 & 0 & $425-700$ & $<=40$ & 0.45 & 0.60 & 0.55 & 0.80 \\
\hline 8 & 0.0 & 0 & 1 & 0 & 1 & 0 & $425-700$ & $40-70$ & 0.50 & 0.65 & 0.60 & 0.80 \\
\hline 9 & 0.0 & 0 & 1 & 0 & 0 & 1 & $425-700$ & $>=70$ & 0.60 & 0.70 & 0.65 & 0.80 \\
\hline 10 & 0.0 & 0 & 0 & 1 & 0 & 0 & $>700$ & $<=40$ & 0.40 & 0.50 & 0.50 & 0.70 \\
\hline 11 & 0.0 & 0 & 0 & 1 & 1 & 0 & $>700$ & $40-70$ & 0.45 & 0.60 & 0.55 & 0.75 \\
\hline 12 & 0.0 & 0 & 0 & 1 & 0 & 1 & $>700$ & $>=70$ & 0.50 & 0.65 & 0.60 & 0.75 \\
\hline 13 & 2.3 & 0 & 0 & 0 & 0 & 0 & $<175$ & $<=40$ & 0.65 & 0.60 & 1.00 & 0.85 \\
\hline 14 & 2.3 & 0 & 0 & 0 & 1 & 0 & $<175$ & $40-70$ & 0.75 & 0.70 & 1.00 & 0.85 \\
\hline 15 & 2.3 & 0 & 0 & 0 & 0 & 1 & $<175$ & $>=70$ & 0.85 & 0.80 & 1.00 & 0.85 \\
\hline 16 & 2.3 & 1 & 0 & 0 & 0 & 0 & $175-425$ & $<=40$ & 0.60 & 0.55 & 0.85 & 0.75 \\
\hline 17 & 2.3 & 1 & 0 & 0 & 1 & 0 & $175-425$ & $40-70$ & 0.70 & 0.65 & 0.85 & 0.75 \\
\hline 18 & 2.3 & 1 & 0 & 0 & 0 & 1 & $175-425$ & $>=70$ & 0.75 & 0.70 & 0.90 & 0.75 \\
\hline 19 & 2.3 & 0 & 1 & 0 & 0 & 0 & $425-700$ & $<=40$ & 0.55 & 0.50 & 0.75 & 0.65 \\
\hline 20 & 2.3 & 0 & 1 & 0 & 1 & 0 & $425-700$ & $40-70$ & 0.60 & 0.55 & 0.75 & 0.65 \\
\hline 21 & 2.3 & 0 & 1 & 0 & 0 & 1 & $425-700$ & $>=70$ & 0.65 & 0.65 & 0.75 & 0.65 \\
\hline 22 & 2.3 & 0 & 0 & 1 & 0 & 0 & $>700$ & $<=40$ & 0.45 & 0.45 & 0.65 & 0.55 \\
\hline 23 & 2.3 & 0 & 0 & 1 & 1 & 0 & $>700$ & $40-70$ & 0.55 & 0.50 & 0.70 & 0.60 \\
\hline 24 & 2.3 & 0 & 0 & 1 & 0 & 1 & $>700$ & $>=70$ & 0.60 & 0.55 & 0.70 & 0.65 \\
\hline 25 & 4.6 & 0 & 0 & 0 & 0 & 0 & $<175$ & $<=40$ & 0.70 & 0.55 & 1.10 & 0.75 \\
\hline 26 & 4.6 & 0 & 0 & 0 & 1 & 0 & $<175$ & $40-70$ & 0.80 & 0.65 & 1.10 & 0.75 \\
\hline 27 & 4.6 & 0 & 0 & 0 & 0 & 1 & $<175$ & $>=70$ & 0.85 & 0.75 & 1.10 & 0.80 \\
\hline 28 & 4.6 & 1 & 0 & 0 & 0 & 0 & $175-425$ & $<=40$ & 0.65 & 0.50 & 0.95 & 0.65 \\
\hline 29 & 4.6 & 1 & 0 & 0 & 1 & 0 & $175-425$ & $40-70$ & 0.75 & 0.60 & 0.95 & 0.65 \\
\hline 30 & 4.6 & 1 & 0 & 0 & 0 & 1 & $175-425$ & $>=70$ & 0.80 & 0.65 & 0.95 & 0.70 \\
\hline 31 & 4.6 & 0 & 1 & 0 & 0 & 0 & $425-700$ & $<=40$ & 0.60 & 0.45 & 0.80 & 0.55 \\
\hline 32 & 4.6 & 0 & 1 & 0 & 1 & 0 & $425-700$ & $40-70$ & 0.65 & 0.50 & 0.80 & 0.60 \\
\hline 33 & 4.6 & 0 & 1 & 0 & 0 & 1 & $425-700$ & $>=70$ & 0.70 & 0.60 & 0.80 & 0.65 \\
\hline 34 & 4.6 & 0 & 0 & 1 & 0 & 0 & $>700$ & $<=40$ & 0.50 & 0.40 & 0.70 & 0.50 \\
\hline 35 & 4.6 & 0 & 0 & 1 & 1 & 0 & $>700$ & $40-70$ & 0.60 & 0.45 & 0.75 & 0.55 \\
\hline 36 & 4.6 & 0 & 0 & 1 & 0 & 1 & $>700$ & $>=70$ & 0.65 & 0.50 & 0.75 & 0.60 \\
\hline 37 & 6.9 & 0 & 0 & 0 & 0 & 0 & $<175$ & $<=40$ & 0.75 & 0.50 & - & 0.70 \\
\hline 38 & 6.9 & 0 & 0 & 0 & 1 & 0 & $<175$ & $40-70$ & 0.85 & 0.60 & - & 0.70 \\
\hline 39 & 6.9 & 0 & 0 & 0 & 0 & 1 & $<175$ & $>=70$ & 0.85 & 0.70 & - & 0.75 \\
\hline 40 & 6.9 & 1 & 0 & 0 & 0 & 0 & $175-425$ & $<=40$ & 0.70 & 0.45 & - & 0.60 \\
\hline 41 & 6.9 & 1 & 0 & 0 & 1 & 0 & $175-425$ & $40-70$ & 0.80 & 0.55 & - & 0.60 \\
\hline 42 & 6.9 & 1 & 0 & 0 & 0 & 1 & $175-425$ & $>=70$ & 0.80 & 0.60 & - & 0.65 \\
\hline 43 & 6.9 & 0 & 1 & 0 & 0 & 0 & $425-700$ & $<=40$ & 0.65 & 0.40 & - & 0.50 \\
\hline 44 & 6.9 & 0 & 1 & 0 & 1 & 0 & $425-700$ & $40-70$ & 0.70 & 0.45 & - & 0.55 \\
\hline 45 & 6.9 & 0 & 1 & 0 & 0 & 1 & $425-700$ & $>=70$ & 0.75 & 0.55 & - & 0.60 \\
\hline 46 & 6.9 & 0 & 0 & 1 & 0 & 0 & $>700$ & $<=40$ & 0.55 & 0.35 & - & 0.45 \\
\hline 47 & 6.9 & 0 & 0 & 1 & 1 & 0 & $>700$ & $40-70$ & 0.60 & 0.40 & - & 0.50 \\
\hline 48 & 6.9 & 0 & 0 & 1 & 0 & 1 & $>700$ & $>=70$ & 0.65 & 0.45 & - & 0.55 \\
\hline
\end{tabular}

Remarks: ': Class A pan placed in short green cropped area, ${ }^{\text {III }}$ Class A pan placed in dry fallow area ${ }^{\text {III }}$ : Colorado sunken pan placed in short green cropped area and ${ }^{\mathrm{IV}}$ : Colorado sunken pan placed in dry fallow area 
The values of variables $X_{2}, X_{3}, X_{4}, X_{5}$ and $X_{6}$ are equal to 0 when the category do not present, or equal to 1 when the category present. Table 2 shows assigned values for these variables. Columns 2-7 are input variables or independent variables and Columns 11-13 are output variables or dependent variables for cases $2-4$, respectively. The multiple linear regression is used to determine regression coefficients.

\section{RESULTS}

The new developed Kp equations based on M5 model tree algorithm and indicator regression for all cases are presented Table 3.

In Eq. 11, the expression $U=425-700,175-425$, $<175$ can be interpreted as follows: if $\mathrm{U}_{2}$ is either 425$700,175-425$, or $<175$, then substitute 1 ; otherwise, substitute 0 . The other expressions in equations 12,14 and 16 can be interpreted in the similar way. The meaning of variables in Eqs. 13, 15 and 17 can be explained as follow. $\mathrm{X}_{1}$ represents $\ln (\mathrm{F}) ; \mathrm{X}_{2}, \mathrm{X}_{3}$ and $\mathrm{X}_{4}$ represent wind run categories of 175-425, 425-700 and $700 \mathrm{~km}^{-1}$, respectively; and $\mathrm{X}_{5}, \mathrm{X}_{6}$ represent relative humidity categories of 40-70, 70\%, respectively. The values of variables $\mathrm{X}_{2}-\mathrm{X}_{5}$ and $\mathrm{X}_{6}$ are equal to 0 when the category not present, or equal to 1 when the category present.

Considering the developed $\mathrm{Kp}$ equations based on M5 model tree, an equation is found for I, II as presented in Eq. 11, 12, respectively. The set of equations are found for cases III, IV, i.e., three rules for case III (Eq. 14) and two rules for case IV (Eq. 16). This may be because the values of standard deviation of the $\mathrm{Kp}$ values for Class A pans are less than those of Colorado sunken pans. The standard deviation of the Kp value for cases I-IV are $0.118,0.121$, 0.160 and 0.157 , respectively. In addition, the range (the difference between maximum and minimum) of the $\mathrm{Kp}$ value for Class A pans (case I, II) are less than those of Colorado sunken pans (case III, IV). Those values are $0.450,0.500,0.600$ and 0.650 for cases I-IV respectively. To evaluate the efficiency of the new proposed Kp equations, the comparison was done by using seven statistical indices, including determination coefficient $\left(\mathrm{R}^{2}\right)$, Root Mean Square Error (RMSE), Mean Absolute Error (MAE), Mean Absolute Relative Error (MARE), Maximum Absolute Relative Error (MXARE), standard deviation of absolute relative error (DEV) and the number of samples with an error greater than $2 \%(\mathrm{NE}>2 \%)$. The $\mathrm{R}^{2}$ measures the degree to which two variables are linearly related and should optimally be one. The RMSE is a measure of the residual standard deviation and should be as small as possible (optimally 0). The MAE, MARE and MXARE measure the difference between actual and estimated $\mathrm{Kp}$ values and should be as small as possible (optimally0).

The actual $\mathrm{Kp}$ values are obtained from Allen (1998) for all cases.

Table 4 summarizes the statistical indices of the new proposed $\mathrm{Kp}$ equations and different existing equations for all study cases as well as Kp estimation using neurogenetic approach as proposed by Ditthakit and Chinnarasri (2011).

Table 3: The new developed Kp equations based on M5 model

\begin{tabular}{|c|c|c|}
\hline \multirow{2}{*}{$\begin{array}{l}\text { Method } \\
\text { Class A pan } \\
\text { placed inshort green } \\
\text { cropped area (Case I }\end{array}$} & \multicolumn{2}{|l|}{ Kp equations } \\
\hline & & \\
\hline M5 model tree & $\begin{array}{l}\mathrm{Kp}=0.0243 \operatorname{In}(\mathrm{F})+0.075 \mathrm{U}_{2}=425-700, \\
175-425,<175+0.075 \mathrm{U}_{2}=175-425,<175 \\
+0.0583 \mathrm{U}_{2}=<175+0.0812 \mathrm{RH} \\
=40-70,>=70+0.0531 \mathrm{RH}=>=70+0.386\end{array}$ & (11) \\
\hline \multicolumn{3}{|c|}{$\begin{array}{l}\text { Class A pan placed in } \\
\text { dry fallow area (Case II) }\end{array}$} \\
\hline M5 model tree & $\begin{array}{l}\mathrm{Kp}=-0.0266 \mathrm{In}(\mathrm{F})+0.0667 \mathrm{U}_{2}=425-700 \\
175-425,<175+0.0708 \mathrm{U}_{2}=175-425,<175 \\
+0.0625 \mathrm{U}_{2}=<175+0.0781 \mathrm{RH} \\
=40-70,>=70+0.0687 \mathrm{RH}=>=70+0.5002\end{array}$ & (12) \\
\hline Indicator regression & $\begin{array}{l}\mathrm{Kp}=0.7000-0.0271 \mathrm{X}_{1}-0.0630 \mathrm{X}_{2}-0.01340 \mathrm{X}_{3} \\
-0.2000 \mathrm{X}_{4}+0.0797 \mathrm{X}_{5}+0.1500 \mathrm{X}_{6}\end{array}$ & (13) \\
\hline \multicolumn{3}{|c|}{$\begin{array}{l}\text { Colorado sunken pan } \\
\text { placed in short green } \\
\text { cropped area (Case III) }\end{array}$} \\
\hline M5 model tree & $\begin{array}{l}\text { Rule: } 1 \text { If } \mathrm{U}_{2}=175-425,<175<=0.5 \text { and } \\
\text { In }(\mathrm{F})>1.15 \text { Then } \\
\mathrm{Kp}=0.0422 \operatorname{In}(\mathrm{F})+0.0625 \mathrm{U}_{2}=425-700, \\
175-425,<175+0.053 \mathrm{U}_{2}=175-425,<175 \\
+0.0556 \mathrm{U}_{2}=<175+0.0259 \mathrm{RH}=40-70, \\
>=70+0.548 \\
\text { Rule: } 2 \text { If } \operatorname{In}(\mathrm{F})<=1.15 \text { Then } \\
\mathrm{Kp}=0.0362 \mathrm{In}(\mathrm{F})+0.05 \mathrm{U}_{2}=425-700,175 \\
-425,<175+0.0833 \mathrm{U}_{2}=175-425,<175 \\
0.1049 \mathrm{U}_{2}=<175+0.0424 \mathrm{RH}=40-70, \\
>=70+0.5218 \\
\text { Rule: } 3 \mathrm{Kp}=0.0399 \operatorname{In}(\mathrm{F})+0.1417 \\
\mathrm{U}_{2}=<175+0.7708\end{array}$ & (14) \\
\hline Indicator regression & $\begin{array}{l}\mathrm{Kp}=0.8358+0.0527 \mathrm{X}_{1}-0.1500 \mathrm{X}_{2} \\
-0.2572 \mathrm{X}_{3}-0.3072 \mathrm{X}_{4}+0.0214 \mathrm{X}_{5}+0.0382 \mathrm{X}_{6}\end{array}$ & (15) \\
\hline \multicolumn{3}{|c|}{$\begin{array}{l}\text { Colorado sunken pan } \\
\text { placed in dry fallow } \\
\text { area (Case IV) }\end{array}$} \\
\hline M5 model tree & $\begin{array}{l}\text { Rule: } 1 \text { If In }(F)>1.15 \text { Then } \\
\mathrm{Kp}=-0.0303 \operatorname{In}(\mathrm{F})+0.0512 \mathrm{U}_{2} \\
=425-700,175-425,<175+0.0831 \\
\mathrm{U}_{2}=175-425,<175+0.1037 \mathrm{U}_{2}=<175 \\
+0.0376 \mathrm{RH}=40-70,>=70+0.6634 \\
\text { Rule: } 2 \mathrm{Kp}=0.0667 \mathrm{U}_{2}=425-700,175-425, \\
<175+0.15 \mathrm{U}_{2}=175-425,<175 \\
+0.15 \mathrm{U}_{2}=<175+0.7333\end{array}$ & \\
\hline Indicator regression & $\begin{array}{l}\mathrm{Kp}=0.9333-0.0362 \mathrm{X}_{1}-0.1000 \mathrm{X}_{2}-0.1833 \mathrm{X}_{3} \\
-0.2333 \mathrm{X}_{4}+0.0167 \mathrm{X}_{5}+0.0500 \mathrm{X}_{6}\end{array}$ & (17) \\
\hline
\end{tabular}


Am. J. Environ. Sci., 8 (2): 95-103, 2012

Table 4: Summary statistical indices of various Kp equations for performance comparisons

\begin{tabular}{|c|c|c|c|c|c|c|c|}
\hline Method & $\mathrm{R}^{2}$ & RMSQ & $\begin{array}{l}\text { MAE } \\
(\%)\end{array}$ & $\begin{array}{l}\text { MARE } \\
(\%)\end{array}$ & $\begin{array}{l}\text { MXARE } \\
(\%)\end{array}$ & $\begin{array}{l}\text { DEV } \\
(\%)\end{array}$ & $\begin{array}{l}\mathrm{NE}> \\
2 \%\end{array}$ \\
\hline \multicolumn{8}{|c|}{ Class A pan placed in short green cropped area (Case I) } \\
\hline M5 model tree (Eq. 11) & 0.9796 & 0.0235 & 1.88 & 2.97 & 8.44 & 2.22 & 21 \\
\hline Cuenca (1989) (Eq. 2) & 0.9601 & 0.0327 & 2.69 & 4.41 & 13.25 & 3.31 & 27 \\
\hline Snyder (1992) (Eq. 3) & 0.9745 & 0.0262 & 2.12 & 3.29 & 9.84 & 2.48 & 21 \\
\hline Raghuwanshi and Wallender (1998) (Eq. 4) & 0.9796 & 0.0235 & 1.88 & 2.97 & 8.46 & 2.22 & 21 \\
\hline Allen (1998) (Eq. 5) & 0.9822 & 0.0235 & 2.72 & 4.07 & 11.46 & 2.85 & 26 \\
\hline Neuro-Genetic & 0.9901 & 0.0167 & 1.40 & 2.29 & 6.18 & 1.63 & 15 \\
\hline \multicolumn{8}{|l|}{ Class A pan placed in dry fallow area (Case II) } \\
\hline M5 model tree (Eq. 12) & 0.9870 & 0.0192 & 1.58 & 2.83 & 9.53 & 2.10 & 16 \\
\hline indicator regression (Eq. 13) & 0.9870 & 0.0192 & 1.58 & 2.83 & 9.58 & 2.10 & 16 \\
\hline Allen (1998) (Eq. 6) & 0.9849 & 0.0383 & 3.11 & 5.02 & 12.90 & 3.20 & 32 \\
\hline Abdel-Wahed and Snyder (2008) (Eq. 7) & 0.9868 & 0.0194 & 1.59 & 2.87 & 10.00 & 2.18 & 16 \\
\hline Neuro-Genetic & 0.9877 & 0.0188 & 1.45 & 2.42 & 8.10 & 2.05 & 17 \\
\hline \multicolumn{8}{|c|}{ Colorado sunken pan placed in short green cropped area (Case III) } \\
\hline M5 model tree (Eq. 14) & 0.9906 & 0.0218 & 1.67 & 2.33 & 6.99 & 2.04 & 12 \\
\hline Indicator regression (Eq. 15) & 0.9699 & 0.0385 & 3.35 & 4.37 & 11.20 & 2.56 & 26 \\
\hline Allen (1998) (Eq. 8) & 0.9840 & 0.0545 & 4.40 & 5.20 & 11.59 & 3.01 & 27 \\
\hline Neuro-Genetic & 0.9921 & 0.0201 & 1.72 & 2.27 & 7.64 & 1.62 & 13 \\
\hline \multicolumn{8}{|c|}{ Colorado sunken pan placed in dry fallow area (Case IV) } \\
\hline M5 model tree (Eq. 16) & 0.9883 & 0.0241 & 1.81 & 2.83 & 10.56 & 2.63 & 18 \\
\hline Indicator regression (Eq. 17) & 0.9536 & 0.0468 & 3.85 & 5.34 & 13.48 & 3.45 & 35 \\
\hline Allen (1998) (Eq. 9) & 0.9851 & 0.0425 & 3.32 & 4.48 & 11.74 & 3.12 & 29 \\
\hline Neuro-Genetic & 0.9890 & 0.0246 & 1.84 & 2.62 & 7.77 & 2.31 & 20 \\
\hline
\end{tabular}

\section{DISCUSSION}

Obviously, neuro-genetic approach can estimte Kp value for all cases better than others. However, unlike using M5 model tree, it cannot be obtained the explicit equation. In case $\mathrm{I}$, the $\mathrm{R}^{2}$ value of $\mathrm{M} 5$ model tree (0.9796) is less than that of Allen (1998) equation (0.9822). The comparable result between M5 model tree (Eq. 11) and Raghuwanshi and Wallender (1998)'s equation (Eq. 4) is found. The values of absolute relative error (\%) obtained from both methods are very close. Both gave less values of RMSQ (0.0235), MAE (\%) (1.88), MARE (\%) (2.97), DEV (\%) (2.22) and $\mathrm{NE}>2 \%$ (21) in comparison to other existing equations. M5 model tree (Eq.11) gives less MXARE value than Raghuwanshi and Wallender (1998)'s equation (Eq.4), 8.44<8.46. It may be concluded that for Class A pan placed in short green cropped area the new $\mathrm{Kp}$ equation as presented in Eq.11 gives a promising performance in estimating $\mathrm{Kp}$ value and can be used as an alternative Kp equation.

In case II, all statistical indices for M5 model tree Eq. 12 and indicator regression Eq. 13 method are almost the same and better than those of Allen (1998) Eq. 6 and Abdel-Wahed and Snyder (2008) Eq. 7. The values of absolute relative error (\%) obtained from M5 model tree Eq. 12 and indicator regression Eq.13 are very close. The M5 model tree gives a little higher performance in estimating $\mathrm{Kp}$ values than Abdel-Wahed and Snyder (2008) method. The MXARE (\%) value using M5 model tree Eq.12 is less than that using indicator regression Eq. 13, 9.53<9.58. This shows that the performance in estimating $\mathrm{Kp}$ values are improved when using M5 model tree. It could suggest two new proposed equations (Eqs. 12 and 13) instead of the previous equations (Eqs. 6 and 7) for this study case.

For case III, the Kp equation based on M5 model tree as expressed in Eq. 14 is rather more cumbersome to apply than other equations due to having three rules in a equation. However, the M5 model tree outperforms indicator regression (Eq. 15) and Allen (1998) equation (Eq. 8) in estimating Kp values. Obviously, M5 model tree gives all statistical indices better than indicator regression and Allen (1998) methods. Hence, this new Kp equation as shown in Eq. 14 can be satisfyingly used to estimate Kp value for this study case.

As explained previously, daily mean wind speed $\left(\mathrm{U}_{2}\right)$ is the categorical data and fetch distance is quantitative data. If the value of this categorical data is less than 0.5 (the average class value of binary variable $(0,1)$ for this case), it means not present in this category; otherwise present in this category. For instance, in Rule 1 of Eq. 14, the meaning of the expression If $U=175-425$, $<175<=0.5$ and $\operatorname{In}(F)>1.15$ can be explained as If $U_{2} \neq$ $175-425$ and $U_{2} \neq<175$ and $\ln (F)>1.15$. 
Am. J. Environ. Sci., 8 (2): 95-103, 2012

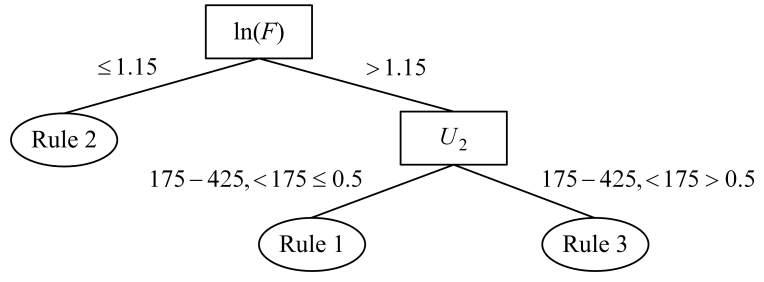

Fig. 2: Illustration of applying M5 model for estimating $\mathrm{Kp}$ value for Case III

The quantitative data like fetch distance can be directly interpreted $\ln (\mathrm{F})>0.15$ means the value of natural logarithm of fetch distance, $\mathrm{F}$ is more than 1.15 meter). For Rule 3, it can give more explaination as follows. If $\operatorname{In}(\mathrm{F})>1.15$ then $\mathrm{Kp}=0.0399 \operatorname{In}(\mathrm{F})+0.1417 \mathrm{U}_{2}=<175+$ 0.7708 . To illustrate of applying M5 model for estimating Kp value, Fig. 2 was drawn as similar to Fig. 1b here.

In case IV, the Kp equation developed by M5 model tree (Eq. 16) is more complex than the other equations. However, the satiable results are obtained with all statistical indices for M5 model tree much better than indicator regression and Allen (1998) equation. Most values of absolute relative error (\%) obtained from M5 model tree (Eq. 16) are less than those obtained from other methods. It may suggest the new Kp equation as presented in Eq.16 to estimate $\mathrm{Kp}$ value for Colorado sunken pan placed in dry fallow area.

\section{CONCLUSION}

To estimate reference evaporation via evaporation pan based method, the pan coefficient (Kp) have to be obtained in addition to pan evaporation data. In this study, the M5 model tree based soft computing approach have been successfully applied for estimating pan coefficient values for both Class A and Colorado sunken Pans under green and dry fetch conditions. In comparison to the existing Pan Coefficient (Kp) equations as well as the new proposed equations based on indicator regression technique, M5 model tree gave more accuracy in estimating Kp values from Kp FAO-24 tables for all cases. Although this method does not outperform neuro-genetic approach in $\mathrm{Kp}$ estimtation, it gave the explicit equations, unlike neuro-genetic aproach. Thus, it indicates the application and usefulness of this technique in developing Kp equations. Based on statistical indices, the new proposed Kp equations can be reliably used.

\section{ACKNOWLEDGEMENT}

This research study is partly supported by Walailak University and Thailand Research Fund (TRF) under grant no. BRG 5280001.

\section{REFERENCES}

Abdel-Wahed, M.H. and R.L. Snyder, 2008. Simple equation to estimate reference evapotranspiration from evaporation pans surrounded by fallow soil. J. Irrig. Drain. Eng., 134: 425-429. DOI: 10.1061/(ASCE)0733-9437(2008)134:4(425)

Allen, R.G. and W.O. Pruitt, 1991. FAO-24 reference evapotranspiration factors. J. Irrig. Drain. Eng., 117: 758-773. DOI: $10.1061 /($ ASCE) 07339437(1991)117:5(758)

Allen, R.G., 1998. Crop Evapotranspiration: Guidelines for Computing Crop Water Requirements. 1st Edn., FAO Irrigation and Drainage Paper 56, Food and Agricultural Organization of the United Nations, Rome, ISBN-10: 9251042195, pp: 300.

Bhattacharya, B. and D.P. Solomatine, 2005. Neural networks and M5 model trees in modelling water level-discharge relationship. Neurocomputing, 63: 381-396. DOI: 10.1016/j.neucom.2004.04.016

Bhattacharya, B. and D.P. Solomatine, 2006. Machine learning in soil classification. Neural Netw., $\quad 19$ : $186-195 . \quad$ DOI: 10.1016/j.neunet.2006.01.005

Cuenca, R.H., 1989. Irrigation System Design: An Engineering Approach. 1st Edn., Prentice-Hall, Englewood Cliffs, N.J., ISBN: 9780135061633. pp: 552.

Ditthakit, P. and C. Chinnarasri, 2011. Estimation of pan evaporation coefficient using Neuro-Genetic approach. Am. J. Environ. Sci., 7: 397-401. DOI: 10.3844/ajessp.2011.397.401

Draper, N. and H. Smith, 1981. Applied Regression Analysis. 2nd Edn., John Wiley and Sons, Inc., New York, ISBN-10: 0471029955, pp: 709.

Frevert, D.K., R.W. Hill and B.C. Braaten, 1983. Estimation of FAO evapotranspiration coefficients. J. Irrig. Drain. Engrg., 109: 265-270. DOI: 10.1061/(ASCE)0733-9437(1983)109:2(265)

Ghare, A.D. and P.D. Porey, 2008. Estimation of reference evapotranspiration of nagpur region using simplified approach. Peroceedings of the 1 st International Conference on Emerging Trends in Engineering and Technology, Jul. 1618, IEEE Xplore Press, Nagpur, Maharashtra, pp: 1022-1028. DIO: 10.1109/ICETET.2008.74

Grismer, M.E., M. Orang, R. Snyder and R. Matyac, 2002. Pan evaporation to reference evapotranspiration conversion methods. J. Irrig. Drain. Eng., 128: 180-184. DOI: 10.1061/(ASCE)0733-9437(2002)128:3(180) 
Gundekar, H.G., U.M. Khodke, S. Sarkar and R.K. Rai, 2008. Evaluation of pan coefficient for reference crop evapotranspiration for semi-arid region. Irrig. Sci., 26: 169-175. DOI 10.1007/s00271-007-0083-y

Hargreaves, G.H. and Z.A. Samani, 1985. Reference crop evapotranspiration from temperature. Applied Eng. Agric., 1: 96-99.

Irmak, S., D.Z. Haman and J.W. Jones, 2002. Evaluation of Class A pan coefficients for estimating reference evapotranspiration in humid location. J. Irrig. Drain. Engrg., 128: 153-159. DOI: 10.1061/(ASCE)0733-9437(2002)128:3(153)

Khoob, A.R., 2009. An evaluation of common pan coefficient equations to estimate reference evapotranspiration in a subtropical climate (north of Iran). Irrig. Sci., 27: 289-296. DOI: 10.1007/s00271-009-0145-4

Milton, J.S. and J.C. Arnold, 1994. Introduction To Probability And Statistics: Principles And Applications For Engineering And Computing Sciences. 3rd Edn., McGraw-Hill, Inc., New York, ISBN-10: 0070426236. pp: 736.

Mitchell, T.M., 1997. Machine Learning. 1st Edn., McGraw-Hill, New York, ISBN: 0070428077, pp: 414.

Mitra, S. and T. Acharya, 2003. Data Mining: Multimedia, Soft Computing and Bioinformatics. 1st Edn., John Wiley and Sons, Inc., Hoboken, New Jersey, ISBN-10: 0471460540, pp: 409.

Orang, M. 1998. Potential accuracy of the popular nonlinear regression equations for estimating pan coefficient values in the original and FAO-24 table. Unpublished, California Department of Water Resources Report, Sacramento, California.

Pal, M., 2006. M5 model tree for land cover classification. Int. J. Remote Sens., 27: 825-831. DOI:10.1080/01431160500256531

Phene, C.J. and R.B. Campbell, 1975. Automating pan evaporation measurements for irrigation control. Agric. For. Meteor., 15:181-191. DOI: 10.1016/0002-1571(75)90003-5

Priestley, C.H.B. and R.J. Taylor, 1972. On the assessment of surface heat flux and evaporation using large-scale parameters. Mon. Weather Rev., 100: 81-92. DOI: 10.1175/15200493(1972)100<0081:OTAOSH>2.3.CO;2

Quinlan, J.R., 1986. Introduction of decision trees. Mach. Learn., 1: 81-106. DOI: 10.1007/BF00116251
Quinlan, J.R., 1992. Learning with continuous classes. Proceedings of the Fifth Australian Joint Conference on Artificial Intelligence, Hobart, Australia, Nov. 16-18, World Scientific, Singapore, pp: 343-348.

Raghuwanshi, N.S. and W.W. Wallender, 1998. Converting from pan evaporation to evapotranspiration, J. Irrig. Drain. Eng., 124: 275-277. DOI: 10.1061/(ASCE)07339437(1998)124:5(275)

Snyder, R.L., 1992. Equation for Evaporation Pan to Evapotranspiration Conversions, J. Irrig. Drain. Eng., 118: 977-980. DOI: 10.1061/(ASCE)07339437(1992)118:6(977)

Snyder, R.L., M. Orang, S. Matyac and M.E. Grismer, 2005. Simplified estimation of reference evapotranspiration from pan evaporation data in California, J. Irrig. Drain. Eng., 131: 249253. DOI: 10.1061/(ASCE)0733-9437(2005)131:3(249)

Solomatine, D.P. and K.N. Dulal, 2003. Model trees as an alternative to neural networks in rainfall-runoff modelling. Hydrol. Sci J., 48: 399-411. DOI: 10.1623/hysj.48.3.399.45291

Solomatine, D.P. and Y. Xue, 2004. M5 model trees and neural networks: application to flood forecasting in the upper reach of the Huai River in China. J. Hydrol. Engrg., 9: 491-501. DOI: 10.1061/(ASCE)1084-0699(2004)9:6(491)

Stanhill, G., 2002. Is the Class A pan evaporationstill the most practical and accurate meteorological method for determining irrigation water requirements? Agric. Meteor., 112: 233-236.

Trajkovic, S., 2009. Comparison of radial basis function networks and empirical equations for converting from pan evaporation to reference evapotranspiration, Hydrol. Process., 23: 874-880. DOI: 10.1002/hyp.7221

Trajkovic, S., B. Todorovic and M. Stankovic, 2001. Estimation of FAO Penman c factor by RBF network. Sci. J. FACTA UNIVERSITATIS: Series Archit. Civil Eng., 2: 185-191.

Trajkovic, S., M. Stankovic and B. Todorovic, 2000. Estimation of FAO blaney-criddle $b$ factor by RBF network. J. Irrig. Drain. Eng., 126: 268-270. DOI: 10.1061/(ASCE)0733-9437(2000)126:4(268)

Turc, L., 1961. Estimation of irrigation water requirements, potential evapotranspiration: A simple climatic formula evolved up to date. Ann. Argon., 12: 13-14.

Witten, I.H. and E. Frank, 2005. Data Mining: Practical Machine Learning Tools and Technique. 3rd Edn., Morgan Kaufmann Publishers, San Francisco, USA., ISBN-10: 0120884070, pp: 664. 